\title{
Assessing the progression of the COVID-19 pandemic in Canada using testing data and time-dependent reproduction numbers
}

\author{
Rojiemiahd Edjoc ${ }^{1} \cdot$ Nicole Atchessi $^{1} \cdot$ Amanda Lien ${ }^{1} \cdot$ Ben A. Smith ${ }^{2} \cdot$ Imran Gabrani-Juma ${ }^{1} \cdot$ Christine Abalos $^{1}$. \\ Marianne Heisz ${ }^{1}$
}

Received: 23 June 2020 / Accepted: 29 September 2020 / Published online: 22 October 2020

(C) The Canadian Public Health Association 2020

\begin{abstract}
Objectives To compare a mathematical tool and time-dependent reproduction number $\left(R_{t}\right)$ estimates to assess the COVID-19 pandemic progression in a Canadian context.

Methods Total number of reported cases were plotted against total number of tests for COVID-19 performed over time, with and without smoothing, for Canada and some Canadian provinces individually. Changes in curvature profile were identified as either convex or concave as indicators of pandemic acceleration or deceleration, respectively. $R_{t}$ estimates were calculated on an exponential growth rate.

Results For Canada as a whole, the testing graphs had a slightly concave profile and a coincident decrease in $R_{t}$ estimates. Saskatchewan more recently had a convex profile with a gradual shift to a concave profile and also demonstrated a gradual decline in $R_{t}$ estimates. Curves and $R_{t}$ estimates for Alberta, British Columbia, Manitoba, Nova Scotia, Ontario and Quebec displayed a gradual shift towards concavity over time and an overall decrease in $R_{t}$ estimates, which is suggestive of a positive impact of public health interventions implemented federally and provincially.

Conclusion The present analyses compared a mathematical tool to $R_{t}$ estimates to ascertain the status of the pandemic in Canada. Caution should be taken when interpreting results due to factors such as varying testing protocols, available testing data unique to each province and limitations inherent to each method, which may generate different results using the two approaches. Analysis of testing data may complement metrics obtained from surveillance data to allow for a weight-of-evidence approach to assess the status of the COVID-19 pandemic.
\end{abstract}

\section{Résumé}

Objectifs Comparer un outil mathématique aux estimations du taux de reproduction en fonction du temps $\left(R_{t}\right)$ pour évaluer la progression de la pandémie de la COVID-19 dans le contexte canadien.

Méthodes Le nombre total de cas signalés a été comparé au nombre total de tests à la COVID-19 effectués au fil du temps, avec et sans lissage, pour le Canada et certaines provinces canadiennes individuellement. Les modifications du profil de courbure identifiées comme étant convexes ou concaves seraient des indicateurs respectivement d'une accélération ou d'une décélération de la pandémie. Le calcul des estimations du $R_{t}$ a été réalisé en fonction du taux de croissance exponentiel.

Résultats Pour l'ensemble du Canada, la légère concavité des graphiques relatifs aux tests coïncidait avec la diminution des estimations du $R_{t}$. Plus récemment, la Saskatchewan avait un profil convexe avec un passage progressif à un profil concave et a également démontré une baisse progressive des estimations du $R_{t}$. Les courbes et les estimations du $R_{t}$ pour l'Alberta, la Colombie-Britannique, le Manitoba, la Nouvelle-Écosse, l'Ontario et le Québec ont montré un glissement progressif vers la

Rojiemiahd Edjoc

rojiemiahd.edjoc@canada.ca

1 Centre for Biosecurity, Public Health Agency of Canada, Ottawa, Ontario, Canada

2 National Microbiology Laboratory, Public Health Risk Sciences Division, Public Health Agency of Canada, Guelph, Ontario, Canada concavité au fil du temps et une diminution globale des estimations du $R_{t}$, ce qui suggère un impact positif des interventions de santé publique mises en œuvre au niveau fédéral et provincial.

Conclusion Les présentes analyses ont comparé un outil mathématique aux estimations de $R_{t}$ pour déterminer l'état de la pandémie au Canada. Les résultats doivent être interprétés avec prudence en raison de certains facteurs tels que les différences entre provinces en ce qui concerne les 
protocoles de réalisation des tests et la disponibilité des données relatives aux tests. De plus, une limite inhérente à la méthodologie de cette étude est la possibilité d'obtenir des résultats différents en fonction de l'approche utilisée. L'analyse des données des tests pourrait être complémentaire à celle des données de surveillance pour permettre une approche fondée sur le poids de la preuve dans le cadre de l'évaluation de l'état de la pandémie de la COVID-19.

Keywords COVID-19 $\cdot$ Canada $\cdot$ Epidemiological surveillance $\cdot$ Time-dependent reproduction number $\cdot$ Public health $\cdot$ Testing

Mots-clés COVID-19 Canada $\cdot$ surveillance épidémiologique $\cdot$ taux de reproduction en fonction du temps $\cdot$ santé publique $\cdot$ tests

\section{Introduction}

Infection from severe acute respiratory syndrome coronavirus 2 (SARS-COV-2) and the subsequent coronavirus disease 2019 (COVID-19) was first detected in Wuhan, China, as early as December 1, 2019 (Huang et al. 2020). On March 11, 2020, the World Health Organization (WHO) declared this outbreak as a global pandemic (World Health Organization 2020). As of June 10, 2020, there were 7,387,000 reported cases from 188 countries, and 417,683 deaths worldwide (Johns Hopkins University 2020).

Despite the early focus on cases in China and the successes of South Korea, the focus had shifted to the stark differences in the pandemic dynamics of European countries such as Italy and Spain. As of April 8, 2020, China began lifting its public health measures and South Korea was able to limit its new cases from March 1, 2020 onwards (Luchini et al. 2020). Their successes came from active physical distancing measures, case detection and contact tracing early on in their respective outbreaks, while countries in Europe and North America were not as active and prompt in implementing their pandemic measures (Luchini et al. 2020). From March 8, 2020 onwards, it was clear that the virus was spreading quickly in many European regions, most notably in France, Italy and others, whereas signs of slowing were already apparent in South Korea (Luchini et al. 2020) (Johns Hopkins University 2020). As of June 8, 2020, Italy had a total of 235,561 confirmed cases, while the United Kingdom had overtaken all of Europe with the highest number of confirmed cases of COVID-19 at 290,581 (Johns Hopkins University 2020).

The virus had spread quickly in the United States and also in Canada. As of June 10, 2020, there were 1,982,264 confirmed cases in the USA and 98,241 in Canada (Government of Canada 2020; Johns Hopkins University 2020). In Canada, within a week of the declaration of COVID-19 as a pandemic, governments at all levels implemented public health response measures. These measures included recommending that gatherings be prevented, closing non-essential businesses, advising the implementation of telework, and closing public meeting places such as restaurants and bars as well as schools and universities. Personal measures included recommending physical distancing and frequent hand washing and limiting non-essential travel (Government of Canada 2020). Shortly thereafter, the Federal government announced the closure of the US and Canadian border to people who were not Canadian citizens or permanent residents, with notable exceptions (Eggertson 2020).

Given the breadth and reach of COVID-19, multiple methods of surveillance are required to assess pandemic progression. We present and compare two methods here: (1) Luchini's mathematical tool and (2) analysis of timedependent reproduction numbers.

Luchini et al. (2020) presented a mathematical tool to estimate the convexity/concavity of trends in epidemiological surveillance data. Pandemic progression is evaluated by measuring changes between pandemic acceleration and pandemic deceleration that are observed in empirical curves using surveillance metrics such as the number of total reported cases over time and the number of total tests per day (Luchini et al. 2020). The resulting plots of convexity (upward curvature) or concavity (downward curvature) which would describe pandemic acceleration or deceleration (respectively) can be used as an adjunct to analysis of surveillance data to explore how the pandemic is evolving.

Other metrics to assess pandemic progression include the calculation of the reproduction number $R . R$ is defined as the number of secondary infections that arise from a typical primary case when an infection is spreading through a completely susceptible population (Wallinga and Lipsitch 2007). The magnitude of $R$ is a useful indicator of the status of an epidemic (Wallinga and Lipsitch 2007). A value of $R$ greater than 1 reflects active community transmission. The time-dependent reproduction number $\left(R_{t}\right)$ is defined as the average number of secondary cases generated by a typical case in a population that may have individuals with some immunity, atypical mixing or may have control measures in place, where an $R_{t}$ of less than 1 will lead to a decrease in the incidence of new cases (Mercer et al. 2011). Similar to Luchini's tool, $R_{t}$ estimates provide a glimpse into pandemic progression.

The primary aim of this paper was to compare the mathematical tool described by Luchini et al. (2020) to $R_{t}$ estimates to evaluate where concordance or non-concordance occurs in relation to the progression of the COVID-19 pandemic in the Canadian context. A comparison between the mathematical tool and $R_{t}$ estimates was performed to evaluate pandemic 
progression within each Canadian province and Canada as a whole.

\section{Methods}

\section{Data sources and variables}

All data used in this study were downloaded from https:// www.canada.ca/en/public-health/services/diseases/2019novel-coronavirus-infection.html\#a1 on June 10, 2020. These data represent the official Government of Canada reported data on (a) total tests performed and (b) total cases by province and territory, on a near daily basis. It should be noted that the total cases reported from this source do not exactly reflect the number of positive diagnostic test results. For example, in Canada, the total case count reported as of 6:00 PM EST on June 10, 2020, was 96,653, while the total positive test count was 89,742 .

For Canada as of June 10, there were 96,653 total cases and a total of 1,955,719 people tested. As of June 10, the provinces that were analyzed were Alberta (total cases, 7229; total tested, 272,967), British Columbia (total cases, 2669; total tested, 135,454), Manitoba (total cases, 300; total tested, 49,296), Nova Scotia (total cases, 1060; total tested, 47,489), Ontario (total cases, 31,090; total tested, 851,609), Quebec (total cases, 53,185; total tested, 493,724) and Saskatchewan (total cases, 656; total tested, 47,247).

\section{Test-case trends}

Analyses were performed using R 3.6.2 (R Core team 2020). Outliers and double entries were identified and inspected while missing data were imputed by cubic spline interpolation using the zoo package (Zeileis and Grothendieck 2005). To replicate Luchini's mathematical tool, raw and smoothed relationships between the total number of tests performed were plotted (x-axis) against total number of confirmed cases (y-axis) over time. Analyses were not performed for New Brunswick, Newfoundland and Labrador, Northwest Territories, Nunavut, Prince Edward Island and Yukon due to insufficient data.

The geom_smooth() function, which uses the optimal local regression (LOESS) smoothing from the ggplot2 package, was applied to the relationship under study (Wickham 2016). The resulting curve presented both point and interval estimates. This approach is similar to the estimated smoothing scatterplot method that uses the Savitzky-Golay filter (Harrell 2015; Luchini et al. 2020; Savitzky and Golay 1964). Raw and estimation curves were superimposed in one graph for clarity and produced for Canada and its provinces. Relevant dates on the same time scale were added for clear comparison with $R_{t}$ estimates described below. Changes in curvature profile were identified as either convex or concave as indicators of pandemic acceleration or deceleration, respectively.

\section{Time-dependent reproduction number estimates}

Analyses were performed using R 3.6.2 (R Core team 2020). Time-dependent reproduction numbers were estimated from an exponential growth rate with a serial interval of mean = 3.99 and standard deviation $=2.96$ using the R0 package (Knight and Mishra 2020; Obadia et al. 2012; Wallinga and Teunis 2004; Wallinga and Lipsitch 2007).

This method is best used for acute diseases with short serial intervals. Diseases with larger incubation times require a more specialized method to account for censoring (Obadia et al. 2012). The starting date for analysis varied between provinces based on the availability of case data for $R_{t}$ analysis. Estimations were made using data from the start date to the most recently available date, where available.

To account for missing dates in the dataset, linear interpolation was applied to estimate the number of new cases and tests performed. This method was chosen over a moving average, as data were not generally smooth. It was assumed that for any days after the province had reported at least 20 cumulative cases, if the number of new cases reported was zero, then the new number of cases may not have been reported. The $95 \%$ confidence intervals were computed by multinomial simulations at each time step with the expected value of $R$ (Obadia et al. 2012). Analyses for New Brunswick, Newfoundland and Labrador, Northwest Territories, Nunavut, Prince Edward Island and Yukon were omitted due to insufficient cases reported resulting in large variability in confidence intervals.

\section{Results}

The relationship between the number of reported cases of COVID-19 and the number of diagnostic tests performed in Canada was established. Figures 1, 2, 3, 4, 5, 6, 7 and 8 represent the curves for Canada as raw data of total number of reported cases and total number of tests and as a spline estimation of the relationship. In general, there was a gradual shift to concavity for Canada as a whole, demonstrating pandemic deceleration.

Figures $1 b, 2 b, 3 b, 4 b, 5 b, 6 b, 7 b$ and $8 b$ represent the timedependent reproduction numbers of various provinces with $95 \%$ confidence intervals. $R_{t}$ estimates for Canada demonstrated an $R_{t}=0.6$ as of June 8, 2020. Similar downward trends were observed for all provinces as of June 8, 2020: Alberta $\left(R_{t}=0.8\right)$, British Columbia $\left(R_{t}=0.6\right)$, Saskatchewan $\left(R_{t}=1.1\right)$, Manitoba $\left(R_{t}=1.2\right)$, Nova Scotia $\left(R_{t}=0.9\right)$, Ontario $\left(R_{t}=0.6\right)$ and Quebec $\left(R_{t}=0.5\right)$. 
Fig. 1 A gradual shift to concavity observed for Canada as a whole beginning May 1, 2020

(a). $R_{t}$ was observed at 1.0 around the same time frame $(\mathbf{b})$
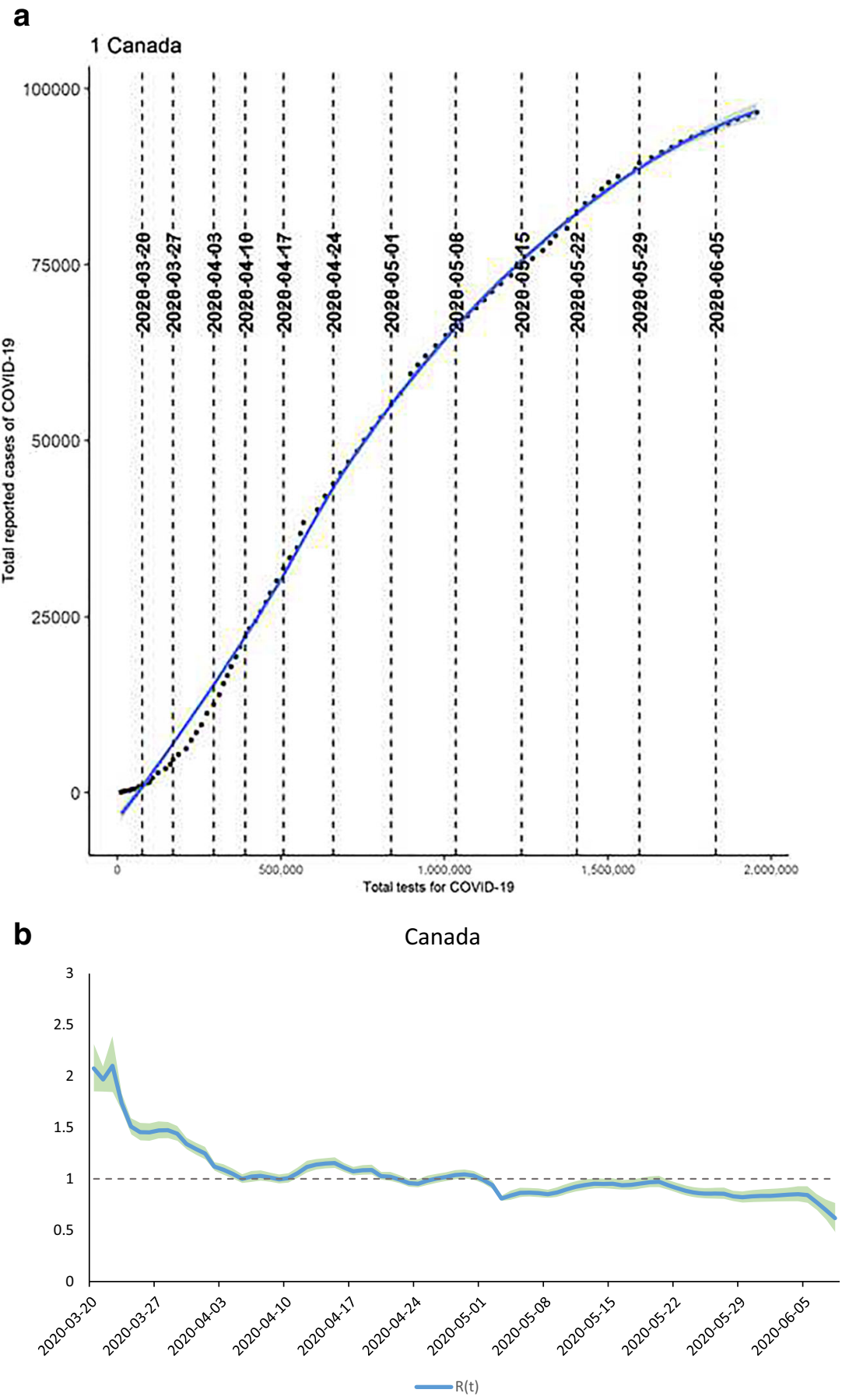

A gradual shift to concavity was observed for Canada as a whole beginning May 1, 2020 (Fig. 1a). $R_{t}$ was observed at 1.0 around the same time frame (Fig. 1b). Alberta demonstrated a shift to concavity around May 1, 2020 (Fig. 2a), while an $R_{t}=0.5$ (Fig. 2b) was observed at the same time point. British Columbia observed a shift to concavity around April 25, 2020 (Fig. 3a), while $R_{t}=0.9$ was observed during the same time (Fig. 3b). Manitoba gradually shifted into concavity around April 6, 2020 (Fig. 4a), and an $R_{t}=0.7$ (Fig. 4b) was observed at the same time point. Nova Scotia, similar to other provinces, gradually shifted into concavity around April 24, 2020 (Fig. 5a), with an $R_{t}=0.6$ observed at the same time (Fig. 5b). Ontario and Quebec gradually shifted in concavity around April 24, 2020 (Fig. 6a), and May 5, 2020 (Fig. 7a), respectively. Observed $R_{t}$ for Ontario and Quebec at the same time points were 0.9 and 
Fig. 2 Alberta demonstrated a shift to concavity around May 1 , 2020 (a), while an $R_{t}=0.5$ (b) was observed at the same time point
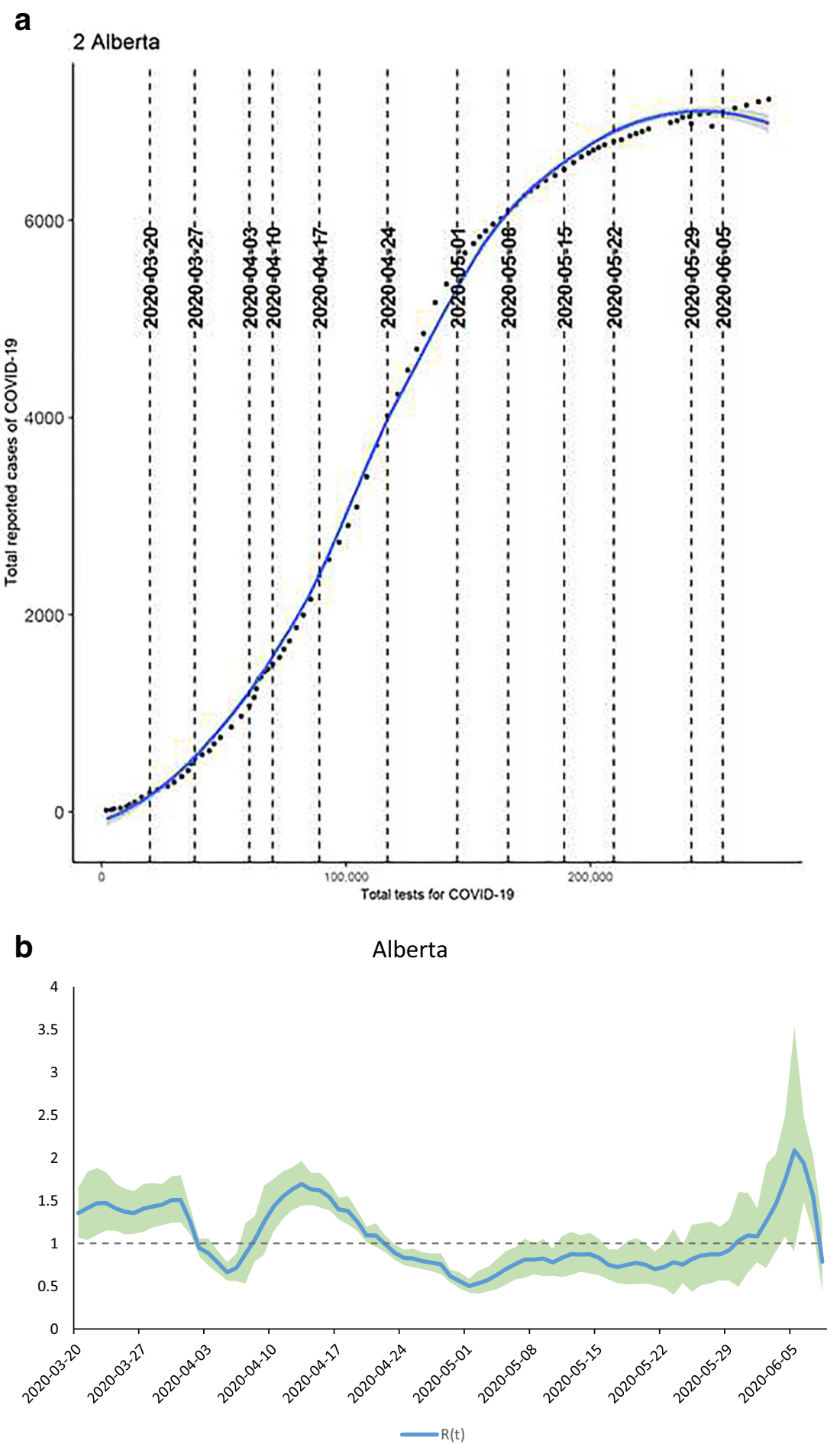

0.9 respectively (Figs. $6 \mathrm{~b}$ and $7 \mathrm{~b}$ ). Saskatchewan had a concave profile up until approximately the 300th case but more recently had a convex profile (April 17, 2020), followed by a subsequent shift back to concavity at around the 550th case (May 8, 2020) (Fig. 8a). In comparison, around those dates for Saskatchewan, $R_{t}$ was observed at 1.3 (April 17, 2020) and 0.5 (May 8, 2020) (Fig. 8b).

\section{Discussion}

The purpose of this study was to analyze the COVID-19 pandemic progression in the Canadian context by using the mathematical tool described by Luchini et al. (2020) and by $R_{t}$ estimates and to assess these methods' concordance and non-concordance. The curve for all Canadian data combined 
Fig. 3 British Columbia observed a shift to concavity around April 25, 2020 (a), while $R_{t}=0.9$ was observed during the same time (b) a

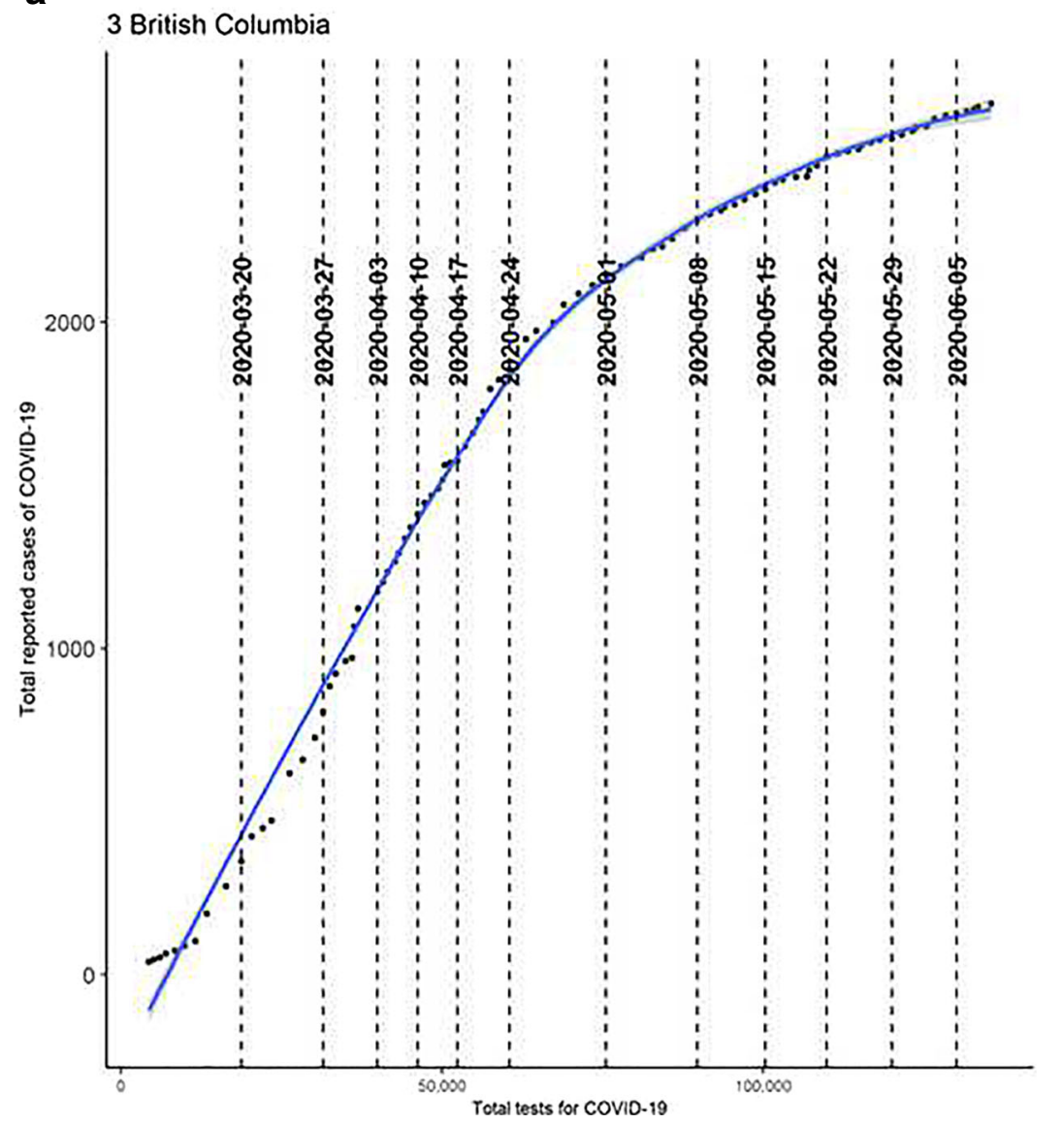

b

British Columbia

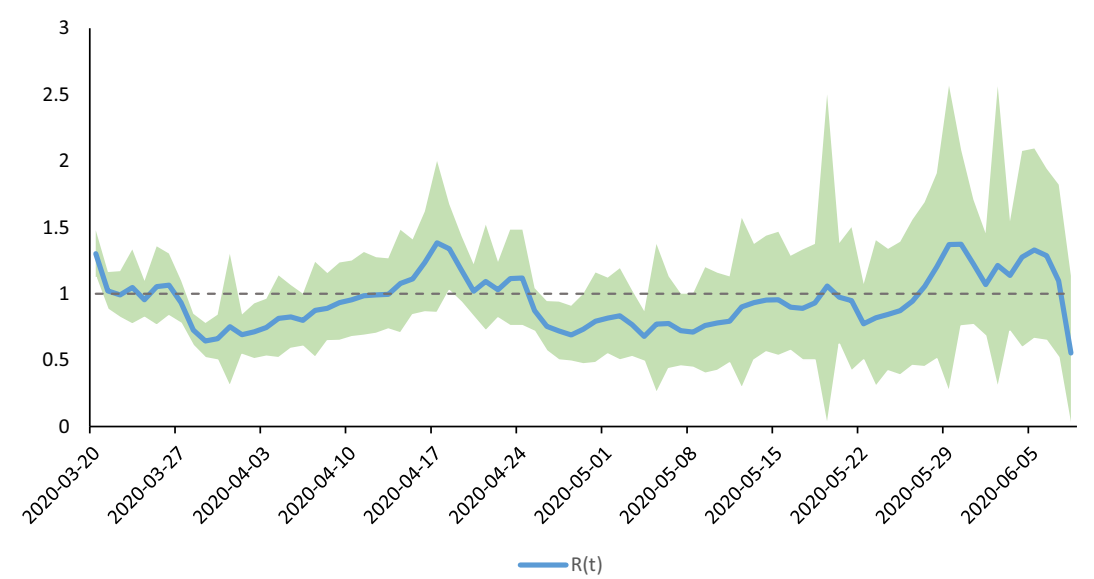

demonstrated a gradual shift towards concavity which suggests that public health measures are generating a positive effect. This was consistent with declining $R_{t}$ values since March 15, 2020.

Saskatchewan demonstrated a concave profile at the beginning of the pandemic but an inflection towards convexity was observed at approximately its 300th case. This was followed by a shift back to a concave profile at approximately its 550th case and onwards. The corresponding date when Saskatchewan reported 550 cases was associated with an outbreak in a northern community (Government of Saskatchewan 2020) around May 8, 2020. The complementary analysis showed that the outbreak was subsequently brought under control, and this was reflected in both the testing curve profile and the $R_{t}$ estimate. Ontario had a gradually shifting profile towards concavity, and similar to the previously discussed provinces, its most recent $R_{t}$ estimates were around 1 at the time of this analysis. Other provinces such as Alberta, British Columbia, Manitoba, Nova Scotia and Quebec had concave profiles and declines in their respective $R_{t}$ estimates. 
Fig. 4 Manitoba gradually shifted into concavity around April 6, 2020 (a), and an $R_{t}=0.7$ (b) was observed at the same time point a

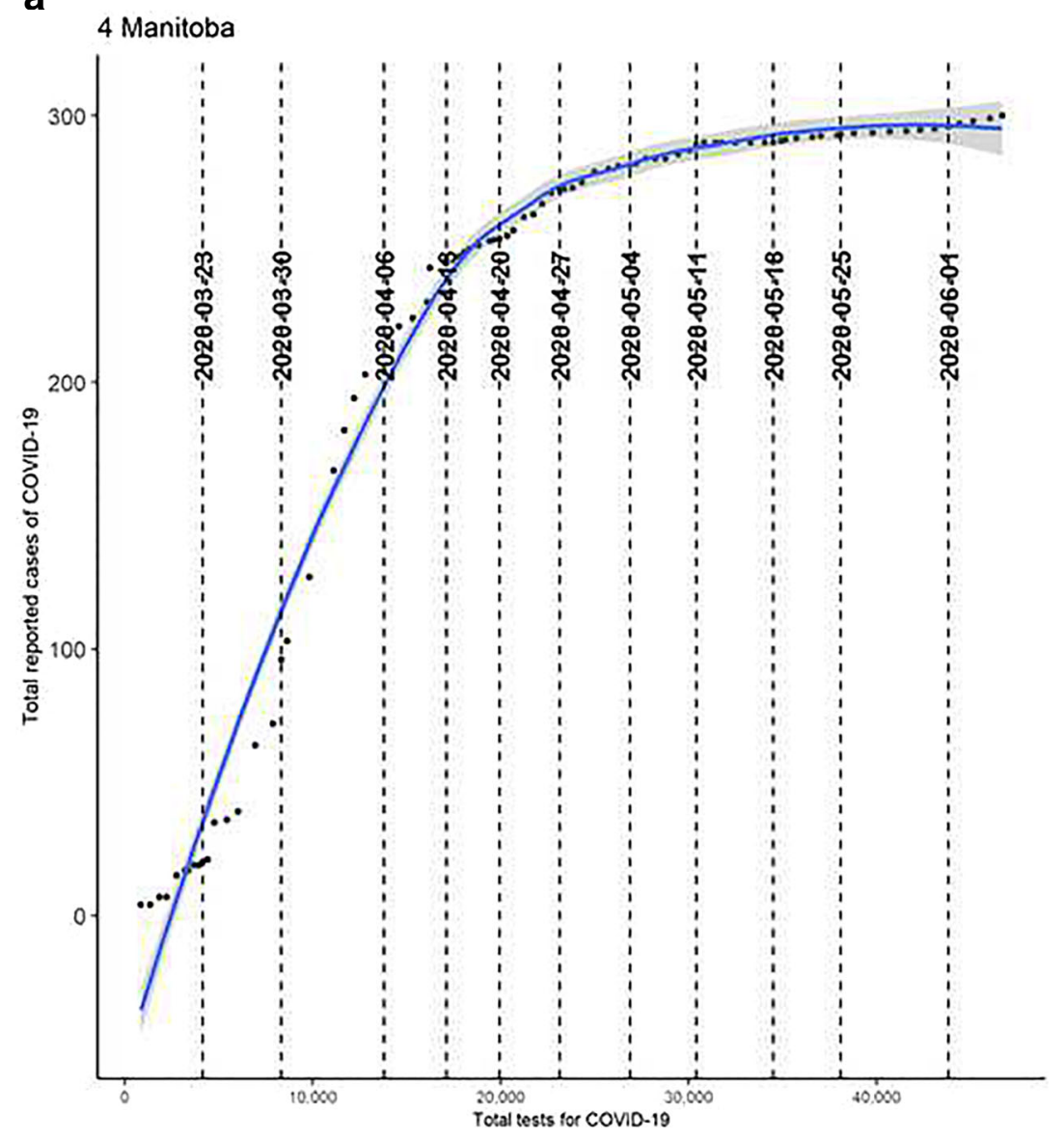

b

Manitoba

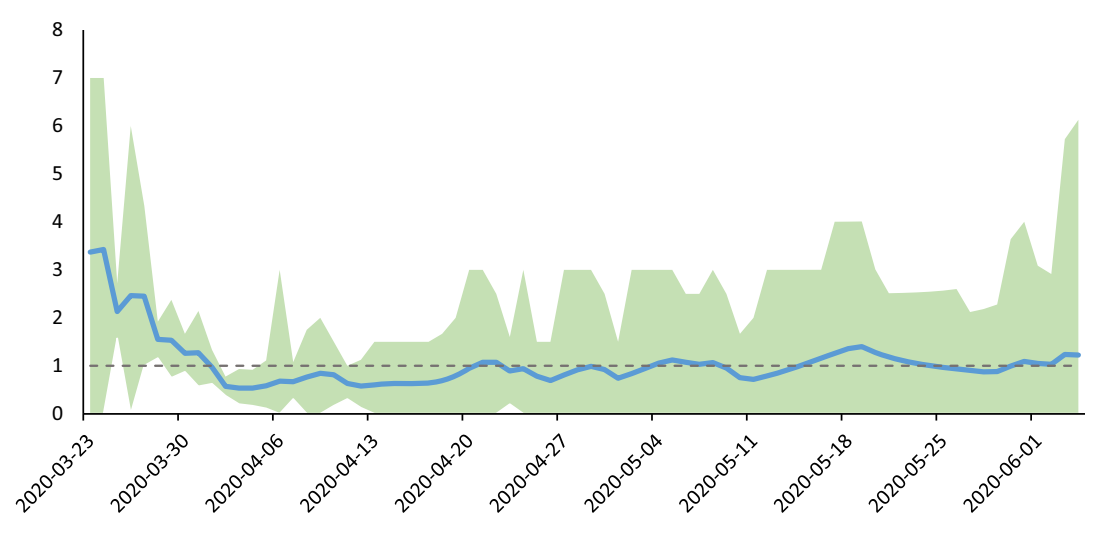

The current analyses demonstrate that a collection of sources can allow for a weight-of-evidence approach to assess the state of the COVID-19 pandemic.

Alberta, Ontario and Quebec have reported the highest numbers of COVID-19 cases per 1000 population in the country (1.47, 1.48 and 4.84 respectively), with the latter reporting more than twice the cases in Canada as of May 15, 2020 (1.96 cases/ 1000 population). This implies more widespread community transmission and therefore a higher reproduction number for these provinces. The goal of public health interventions is to reduce $R$ to a value below 1 (Wallinga and Teunis 2004) which leads to a decrease of newly infected people over time. However, there is an expected delay between the implementation of public health measures and the visibility of their impacts. For example, in regions outside Canada, containment and quarantine measures were implemented to manage the growing spread of COVID-19 within and among communities. As a result, the mobility of individuals decreased gradually and a decrease of community 
Fig. 5 Nova Scotia, similar to other provinces, gradually shifted into concavity around April 24, 2020 (a), with an $R_{t}=0.6$

observed at the same time (b) a

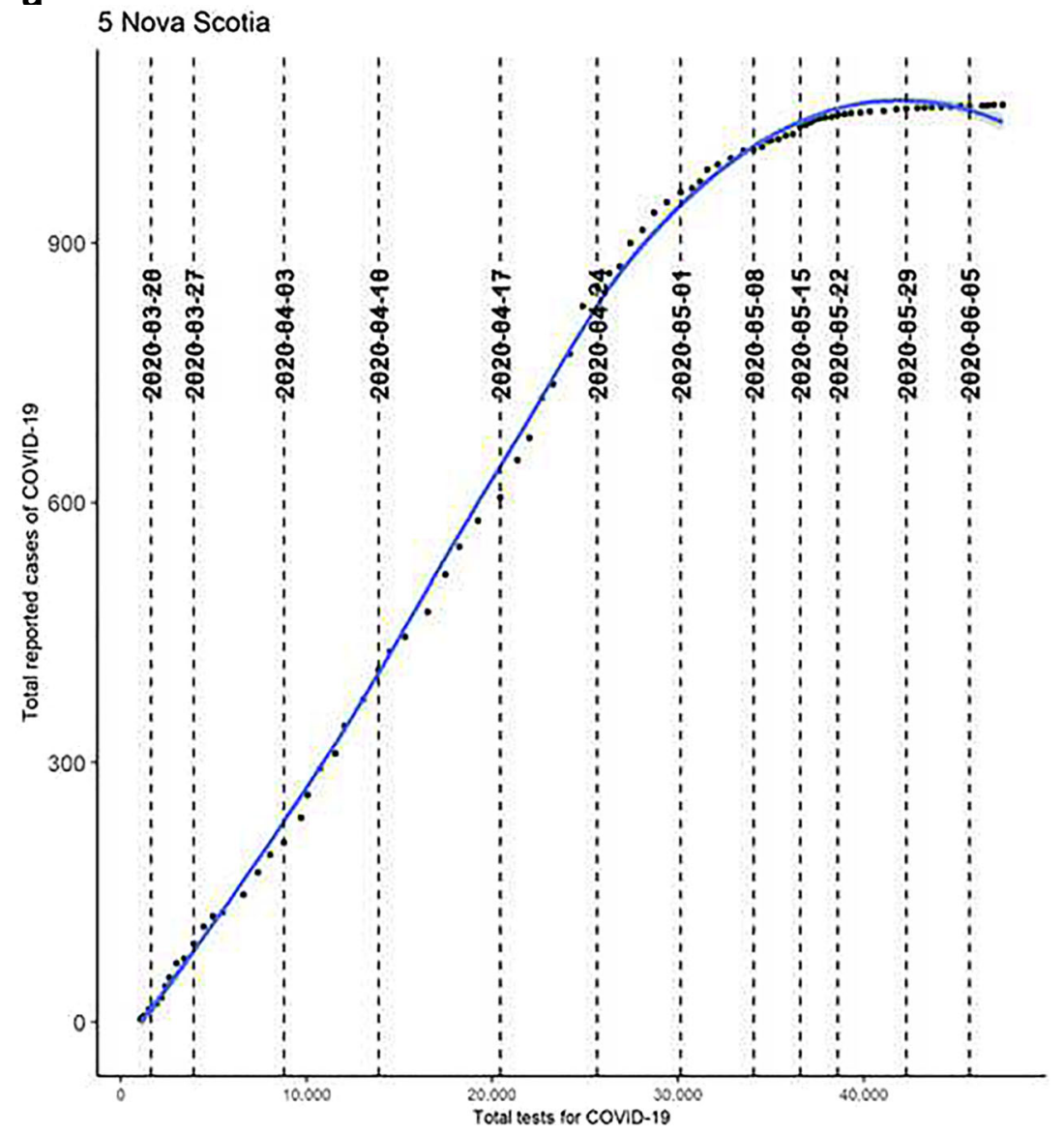

b

Nova Scotia

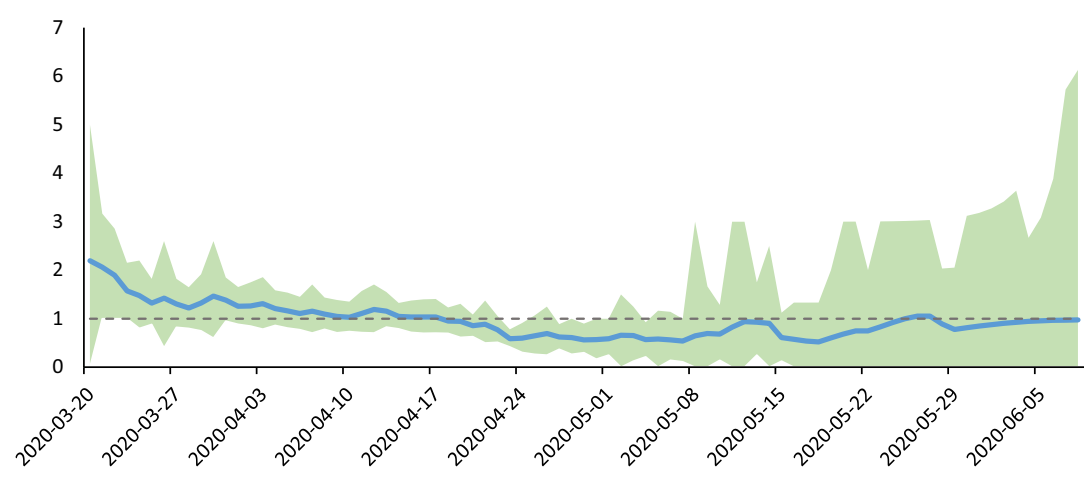

transmission was subsequently observed (Kraemer et al. 2020). The delay between the implementation of public health interventions and their impacts can vary from 2 weeks to a month and may be influenced by several factors (Kraemer et al. 2020; Shi and Fang 2020; Zhang et al. 2020). Such factors may include whether a single intervention or combination of several types of interventions are implemented, and in the case of the latter, whether different measures are executed simultaneously or gradually over time (Tian et al. 2020; Ying et al. 2020). Other factors might include the stage of the epidemic or pandemic progression at which the public health intervention was implemented and how well they are adhered to (Drake 2020; Qiu and Xiao 2020).

In Canada, although various types of interventions were implemented, they were executed in succession over weeks as opposed to concurrently, thus the delay between their implementation and their impacts will still exist as part of the normal process of an intervention. Furthermore, it is worthwhile to explore whether public health measures were effectively implemented and adhered to. Although the application of containment rules could be objectively quantified by 
Fig. 6 Ontario gradually shifted in concavity around April 24, 2020 (a). Observed $R_{t}$ for Ontario was 0.9 (b)

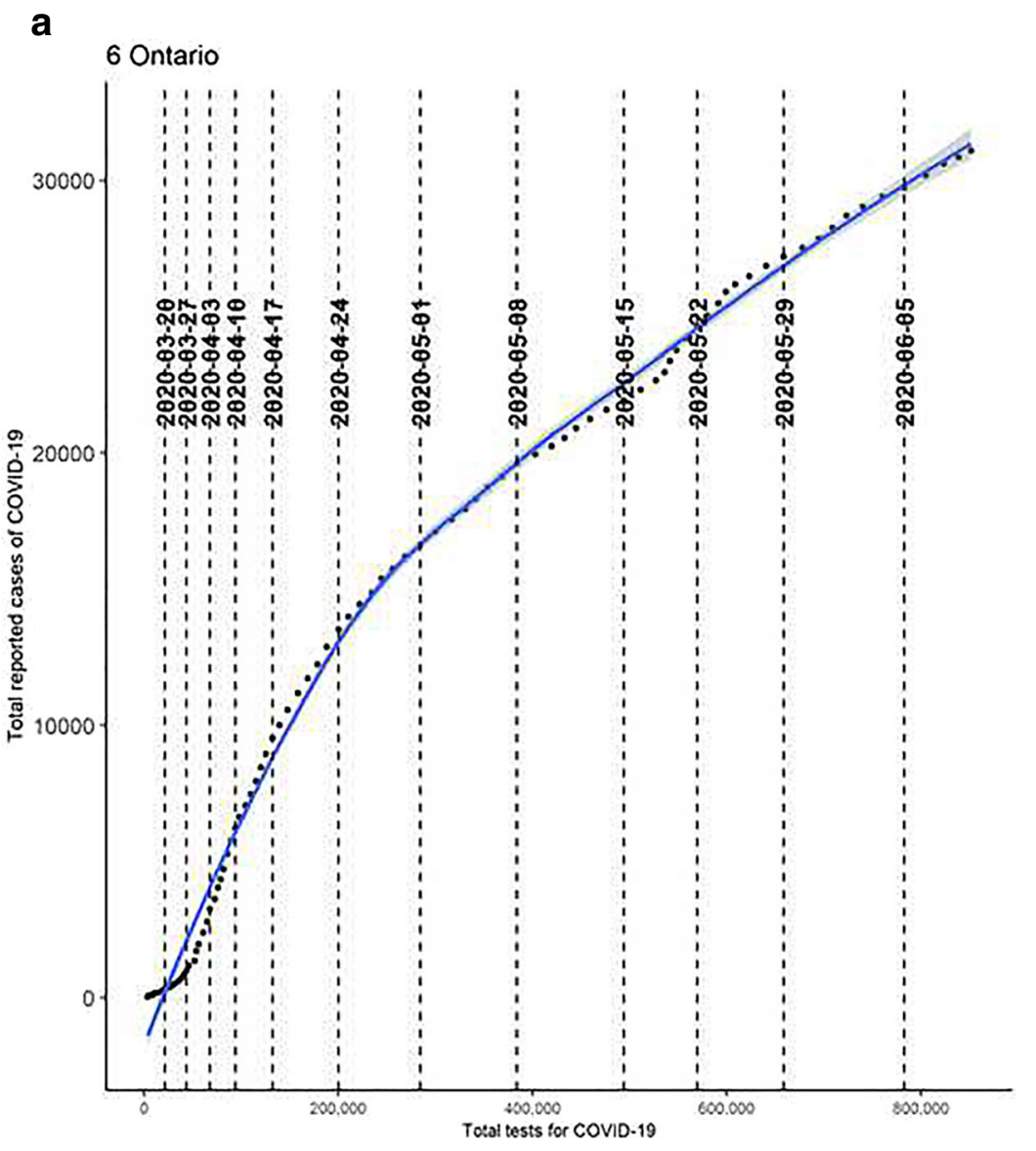

b

Ontario

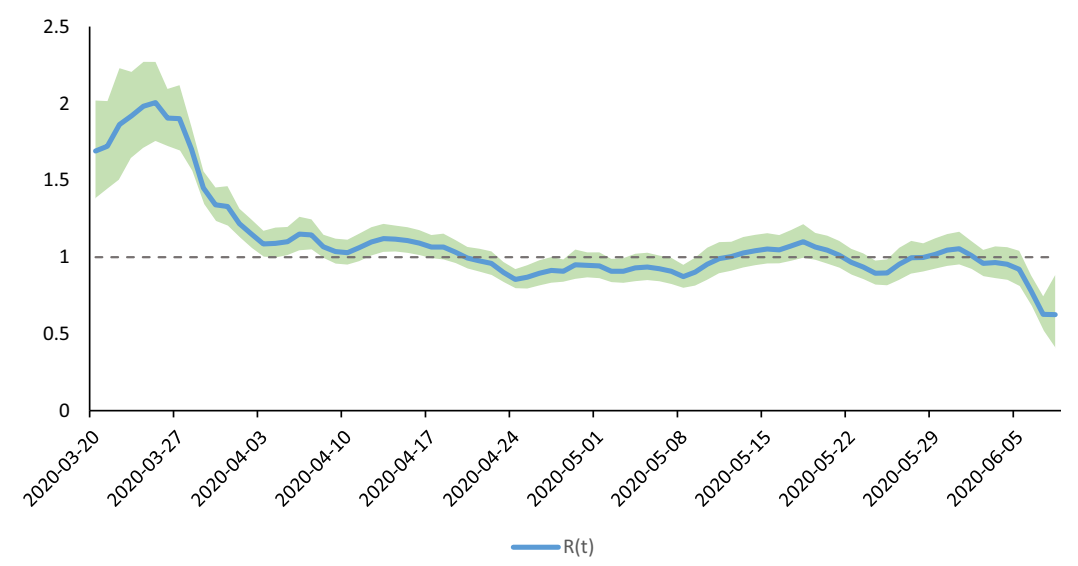

measuring the mobility of a population (Shi and Fang 2020), the measure of change in individual behaviour such as adherence to physical distancing and hygiene recommendations is challenging. Surveys, for example, have limitations due to possible social desirability bias that could overestimate actual changes (Krumpal 2013). Therefore, before concluding the ineffectiveness or effectiveness of an intervention, it would be worthwhile to explore all aspects related to its uptake and the likely possibility of delayed effects.
The Luchini et al. (2020) mathematical tool for measuring the effectiveness of interventions could serve alongside other metrics as a practical tool for stakeholders to visually understand the progression of the pandemic. One of the strengths of this approach is that it takes into consideration, albeit generally, the influence of testing on reported cases. For example, a surge in case counts (and increasing $R_{t}$ estimate) could simply be a reflection of a corresponding surge in testing, but this would be accounted for with analysis of testing data by 
Fig. 7 Quebec gradually shifted in concavity around May 5, 2020 (a). Observed $R_{t}$ for Quebec was 0.9 (b)
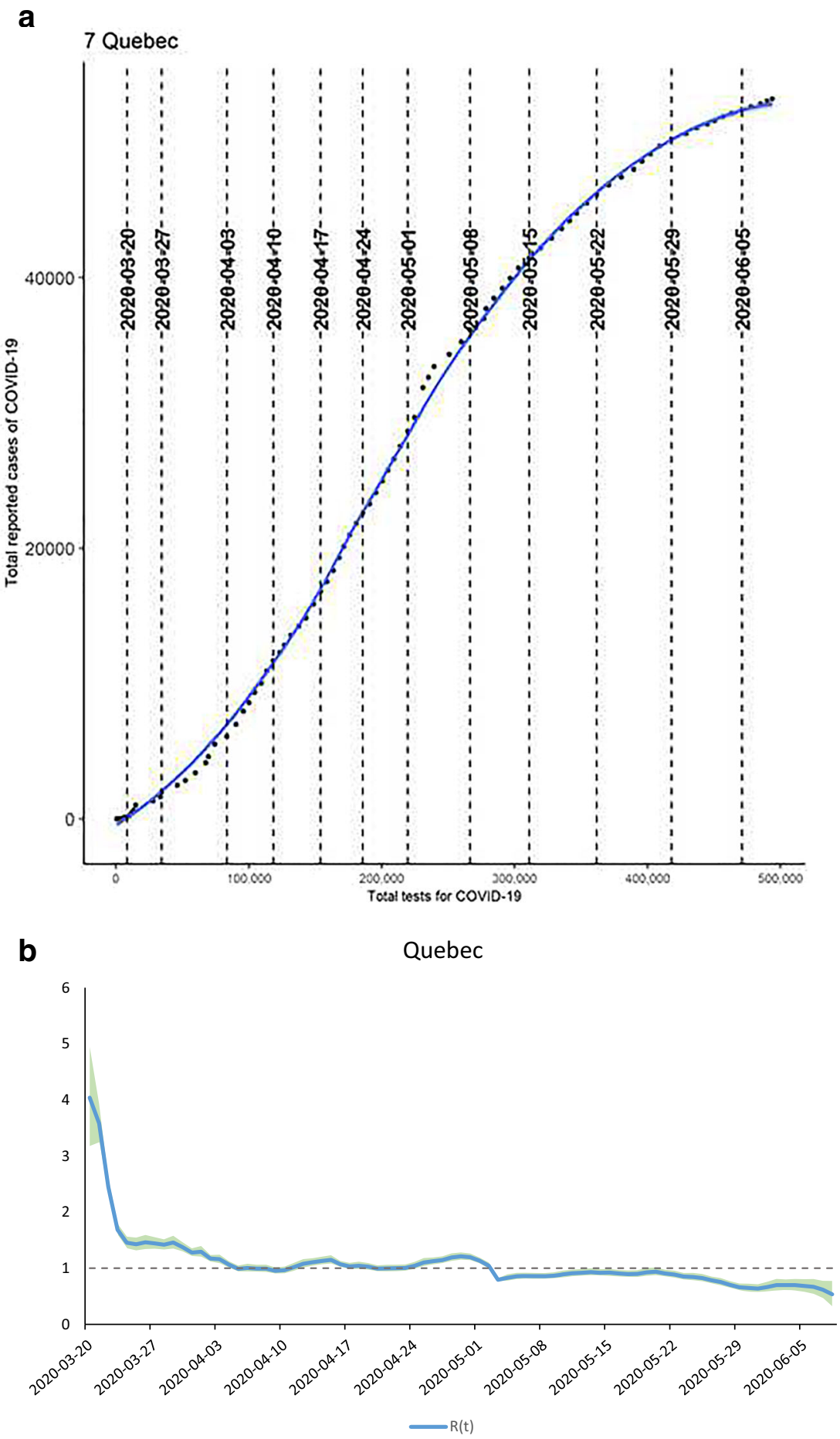

capturing an increase in testing volume. Nevertheless, if testing does not change, $R_{t}$ estimates provide a near real-time analysis of the status of transmission within the population (Ridenhour et al. 2014).

This being said, there are some limitations with both approaches. The Luchini et al. (2020) method solely relies upon a phenomenological approach, which describes the phenomenon (pandemic progression) as a generic mathematical function (after smoothing the observations) of the incidence time series (Luchini et al. 2020). This function is then used to generate estimates, presented as either a convex or concave relationship, which then serves as an indication of pandemic acceleration or deceleration, respectively (Luchini et al. 2020). This approach does not take into account mechanistic considerations such as the average number of secondary cases (i.e., $R_{t}$ ) stemming from incident cases, which have a profound effect on pandemic acceleration or deceleration (Cori et al. 2013). This lack of mechanistic factors inherent to the 
Fig. 8 Saskatchewan had a concave profile up until approximately the 300 th case but more recently had a convex profile (April 17, 2020), followed by a subsequent shift back to concavity at around the 550th case (May 8, 2020) (a). In comparison, around those dates for Saskatchewan, $R_{t}$ was observed at 1.3 (April 17, 2020) and 0.5 (May 8, 2020) (b) a

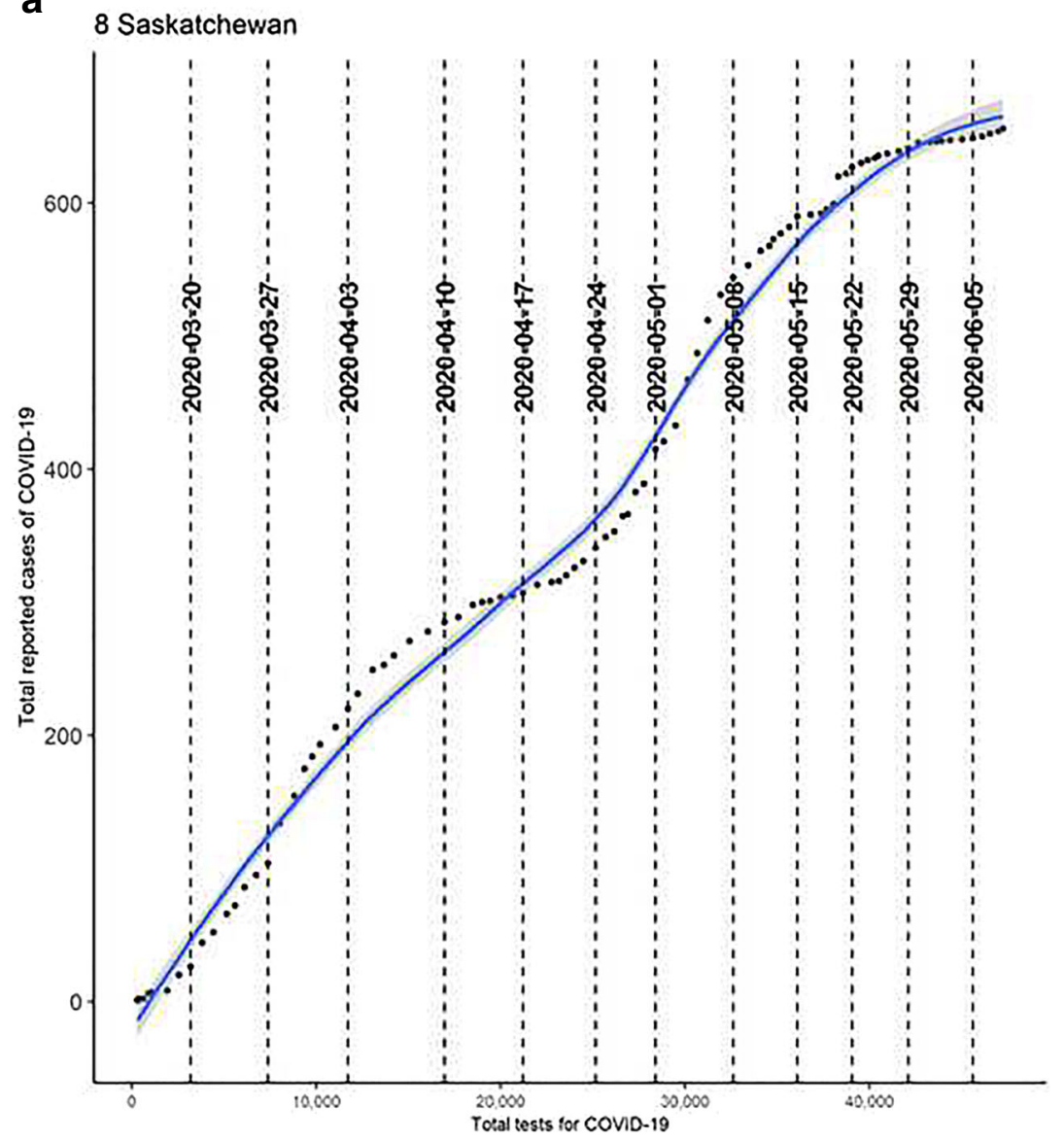

b

Saskatchewan

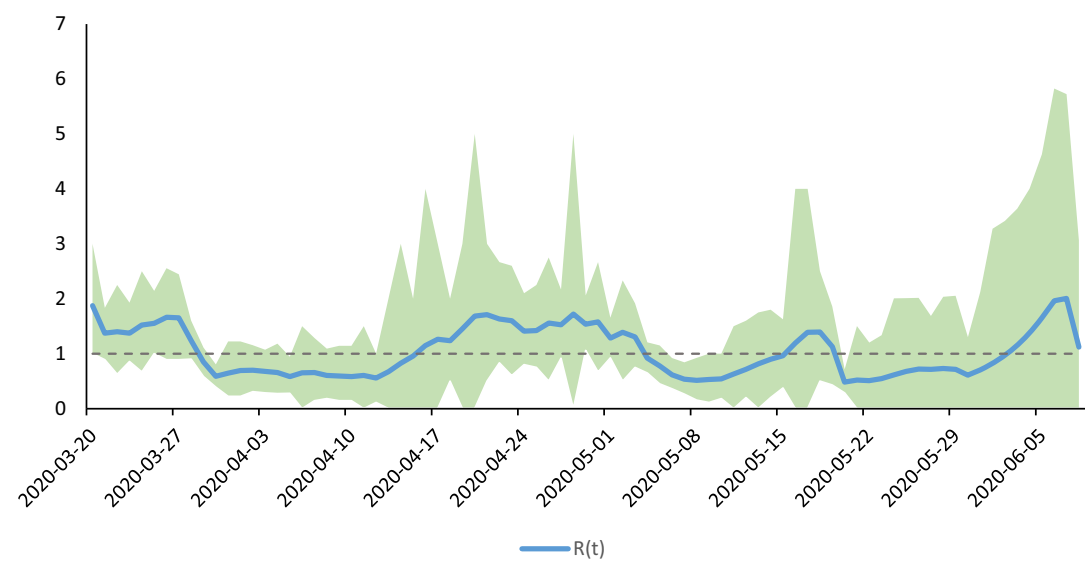

Luchini et al. (2020) method may contribute to the differences observed between its results and calculated $R_{t}$ estimates. Other limitations include instances when several interventions are in play. In such cases, the tool does not allow for differentiation of interventions. Therefore, it is unable to allow for the identification of more or less effective measures. Furthermore, the imputation for missing data by linear interpolation is a method that can lead to imprecision in the estimates.
There are also issues related to COVID-19 testing that present a limitation to this approach. For instance, delays in testing and confirmation of results can prevent the application of the approach. It is also uncertain exactly which proportion of test results represent the same individuals. For instance, several tests could have been performed on the same individual. Another limitation would be the issue of intra- and interprovincial variation in terms of who is tested for COVID-19. 
This highlights the need for caution when comparing the results of jurisdictions. In fact, testing strategies in Canada have evolved and continue to evolve over time. While testing strategies first focused on travellers or close contacts of travellers at the start of the outbreak, they gradually expanded to the general population of communities (Health Canada 2020). As of April 2020, British Columbia and Quebec focused their testing efforts on hospitalized people, those developing complications, and residents and staff of long-term care facilities (Health Canada 2020). Ontario expanded its testing criteria to residents and staff of homeless shelters and cancer patients living with health workers (Health Canada 2020). Meanwhile, Alberta expanded testing to asymptomatic persons (Health Canada 2020). The incidence of COVID-19 in these subpopulations could, in some cases, be greater than in the general population. Overall, these limitations could generate inaccuracies and influence model results and interpretations while discrepancies in testing criteria between provinces and territories result in an inability to directly compare the pandemic progression among them.

$R_{t}$ estimates similarly have inherent limitations, particularly with the Wallinga and Teunis (2004) method. This method does not measure instantaneous transmissibility where estimates do not change immediately after interventions are altered and may not demonstrate what is actually occurring during transmission (Wallinga and Teunis 2004). A second limitation inherent to these estimates is the transmission potential, such as the value of R0 (Lipsitch and Bergstrom 2004). For example, differences in the degree of infectiousness or duration of infectious period among individuals (i.e., differences in viral shedding) will result in the number of secondary infections per person to be over-dispersed (Lipsitch and Bergstrom 2004). Disentangling the contributions of both limitations to $R_{t}$ estimates requires further information, such as when interventions were implemented (Wallinga and Teunis 2004). As well, the derivation of $R_{t}$ is dependent on the serial interval of COVID-19, which is highly uncertain. For the present analyses, serial interval was chosen from a Canadian study in the Greater Toronto Area to reflect transmission dynamics within a Canadian context (Knight and Mishra 2020). However, as the pandemic continues to evolve, these metrics would need to be continually re-evaluated or even replaced, depending on the data that would be available. Last, as described by Obadia et al. (2012), this method does not account for under-reporting, reporting delays, and importation of cases, all of which may bias the overall estimate.

\section{Conclusion}

The present analyses compared the mathematical tool described by Luchini et al. (2020) with $R_{t}$ estimates to ascertain the status of the COVID-19 pandemic in Canada. However, though results from both approaches are concordant in certain provinces, they are also non-concordant in others. These differences may be explained by the limitations of each method that underscore the need for a collection of sources to allow for a weight-of-evidence approach to assess the state of the COVID-19 pandemic. Further evaluation of both methods is required as more data are acquired to assess its utility in the Canadian context.

Acknowledgements We would like to acknowledge and thank the Provinces and Territories for their support in this research and continued collaboration. Without their support, this work would not be possible. We also acknowledge Dr. Nicholas Ogden of the Public Health Agency of Canada for his support and insights on this work.

\section{Compliance with ethical standards}

Conflict of interest The authors declare that they have no conflict of interest.

\section{References}

Cori, A., Ferguson, N. M., Fraser, C., \& Cauchemez, S. (2013). A new framework and software to estimate time-varying reproduction numbers during epidemics. American Journal of Epidemiology, 178(9), 1505-1512. https://doi.org/10.1093/aje/kwt133.

Drake, J. M. (2020). Time to containment of COVID-19 in China. Georgia University. Retrieved from http://2019-coronavirustracker.com/early-intervention.html. Accessed 23 June 2020.

Eggertson, L. (2020). COVID-19: Recent updates on the coronavirus pandemic. Retrieved from https://cmajnews.com/2020/04/14/ coronavirus-1095847/. Accessed 23 June 2020.

Government of Canada. (2020). Coronavirus disease (COVID-19): Outbreak update. Retrieved from https://www.canada.ca/en/publichealth/services/diseases/2019-novel-coronavirus-infection.html. Accessed 23 June 2020

Government of Saskatchewan. (2020). COVID-19 outbreaks in Saskatchewan. Retrieved from https://www.saskatchewan.ca/ government/health-care-administration-and-providerresources/treatment-procedures-and-guidelines/emergingpublic-health-issues/2019-novel-coronavirus/latest-updates. Accessed 23 June 2020.

Harrell, F. (2015). Regression modeling strategies Springer series in statistics.

Health Canada. (2020). Federal/provincial/territorial COVID-19 interventions. Internal document. Unpublished manuscript. Retrieved 2020-04-21.

Huang, C., Wang, Y., Li, X., Ren, L., Zhao, J., Hu, Y., . . Cao, B. (2020). Clinical features of patients infected with 2019 novel coronavirus in Wuhan, China. Lancet (London, England).

Johns Hopkins University. (2020). Coronavirus resource center. Retrieved from https://coronavirus.jhu.edu/map.html. Accessed 10 June 2020.

Knight, J., \& Mishra, S. (2020). Estimating effective reproduction number using generation time versus serial interval, with application to COVID-19 in the greater Toronto area, Canada. MedRxiv.

Kraemer, M. U. G., Yang, C. H., Gutierrez, B., Wu, C. H., Klein, B., Pigott, D. M., et al. (2020). The effect of human mobility and control measures on the COVID-19 epidemic in China. Science. https://doi. org/10.1126/science.abb4218. 
Krumpal, I. (2013). Determinants of social desirability bias in sensitive surveys: A literature review. Quality and Quantity, 47(4), 20252047. https://doi.org/10.1007/s11135-011-9640-9.

Lipsitch, M., \& Bergstrom, C. T. (2004). Invited commentary: Real-time tracking of control measures for emerging infections. American Journal of Epidemiology, 160(6), 517-519 discussion 520

Luchini, L., Teschl, M., Pintus, B., Degoulet, M., Baunez, C., \& Moatti, J. P. (2020). Urgently needed for policy guidance: An operational tool for monitoring the COVID-19 pandemic. SSRN. https://doi.org/ $10.2139 /$ ssrn.3563688.

Mercer, G. N., Glass, K., \& Becker, N. G. (2011). Effective reproduction numbers are commonly overestimated early in a disease outbreak. Statistics in Medicine, 30(9), 984-994. https://doi.org/10.1002/sim. 4174.

Obadia, T., Haneef, R., \& Boëlle, P. Y. (2012). The R0 package: A toolbox to estimate reproduction numbers for epidemic outbreaks. BMC Medical Informatics and Decision Making, 12, 147. https:// doi.org/10.1186/1472-6947-12-147.

Qiu, T., \& Xiao, H. (2020). Revealing the influence of national public health policies for the outbreak of the SARS-CoV-2 epidemic in Wuhan, China through status dynamic modeling. MedRxiv, 2020(03), 10.20032995. https://doi.org/10.1101/2020.03.10. 20032995.

Ridenhour, B., Kowalik, J. M., \& Shay, D. K. (2014). Unraveling R0: Considerations for public health applications. American Journal of Public Health, 104(2), e32-e41. https://doi.org/10.2105/AJPH. 2013.301704.

R Core Team. (2020). R: A language and environment for statistical computing. Vienna: R Foundation for Statistical Computing. https://www.R-project.org. Accessed 23 June 2020.

Savitzky, A., \& Golay, M. (1964). Smoothing and differentiation of data by simplified least squares procedures. Analytical Chemistry, 36(8), $1627-1639$

Shi, Z., \& Fang, Y. (2020). Temporal relationship between outbound traffic from Wuhan and the 2019 coronavirus disease (COVID-19) incidence in China. MedRxiv, 2020(03), 15.20034199. https://doi. org/10.1101/2020.03.15.20034199.
Tian, H., Liu, Y., Li, Y., Wu, C. H., Chen, B., Kraemer, M. U. G., et al. (2020). An investigation of transmission control measures during the first 50 days of the COVID-19 epidemic in China. Science. https://doi.org/10.1126/science.abb6105.

Wallinga, J., \& Lipsitch, M. (2007). How generation intervals shape the relationship between growth rates and reproductive numbers. Proceedings of the Biological Sciences, 274(1609), 599-604. https://doi.org/10.1098/rspb.2006.3754.

Wallinga, J., \& Teunis, P. (2004). Different epidemic curves for severe acute respiratory syndrome reveal similar impacts of control measures. American Journal of Epidemiology, 160(6), 509-516. https:// doi.org/10.1093/aje/kwh255.

Wickham, H. (2016). ggplot2-elegant graphics for data analysis (2nd ed.). New York: Springer.

World Health Organization. (2020). WHO Director-General's opening remarks at the media briefing on COVID-19 - 11 March 2020. Retrieved from https://www.who.int/dg/speeches/detail/whodirector-general-s-opening-remarks-at-the-media-briefing-oncovid-19\%2D\%2D-11-march-2020. Accessed 23 June 2020.

Ying, S., Li, F., Geng, X., Li, Z., Du, X., Chen, H., et al. (2020). Spread and control of COVID-19 in China and their associations with population movement, public health emergency measures, and medical resources. MedRxiv. https://doi.org/10.1101/2020.02.24.20027623.

Zeileis, A., \& Grothendieck, G. (2005). Zoo: S3 infrastructure for regular and irregular time series. Journal of Statistical Software; 1, Issue 6. Retrieved from https://www.jstatsoft.org/v014/i06; https://doi.org/ 10.18637/jss.v014.i06. Accessed 23 June 2020.

Zhang, Y., Jiang, B., Yuan, J., \& Tao, Y. (2020). The impact of social distancing and epicenter lockdown on the COVID-19 epidemic in mainland China: A data-driven SEIQR model study. MedRxiv, 2020(03), 04.20031187. https://doi.org/10.1101/2020.03.04. 20031187.

Publisher's note Springer Nature remains neutral with regard to jurisdictional claims in published maps and institutional affiliations. 